\title{
Ethical Considerations for Restrictive and Physical Distancing Measures in Brazil During COVID-19: Facilitators and Barriers
}

\author{
Beatriz C. Thomé (1) • Gustavo C. Matta • Sérgio T. A. Rego
}

Received: 1 May 2020 / Accepted: 3 August 2020

(C) Journal of Bioethical Inquiry Pty Ltd. 2020

\begin{abstract}
COVID-19 was recognized as a pandemic on March 11, 2020. Nine days later in Brazil, community transmission was deemed ongoing, and following what was already being put in place in various affected countries, restrictive and physical distancing measures that varied in severity across the different states were adopted. Adherence to restrictive and physical distancing measures depends on the general acceptance of public health measures as well as communities' financial leverage. This article aims to explore and discuss ethical facilitators and barriers to the implementation of physical distancing measures within three dimensions: political, socio-economic, and scientific. Furthermore,
\end{abstract}

Dr. Sérgio T.A. Rego is a fellow researcher of the National Council for Scientific and Technological Development (CNPq) in Brazil.

\section{B. C. Thomé $(\square)$}

Departamento de Medicina Preventiva, Universidade Federal de São Paulo, Rua Botucatu, 740, 4th floor, room 457, São Paulo, SP 04023-062, Brazil

e-mail: beatriz.thome@unifesp.br

G. C. Matta

Oswaldo Cruz Foundation - FIOCRUZ, Rua Leopoldo Bulhões, 1480 Room 716, Rio de Janeiro, RJ 21041210, Brazil

e-mail: gcmatta@ensp.fiocruz.br

S. T. A. Rego

National School of Public Health Sergio Arouca, Oswaldo Cruz Foundation-FIOCRUZ, Rua Leopoldo Bulhões, 1480 Room 919, Rio de Janeiro, RJ 21041210, Brazil

e-mail: rego@ensp.fiocruz.br we would like to discuss ways to ethically promote restrictive and physical distancing measures in a large and unequal country like Brazil. There is an urgent need for transparent, consistent, and inclusive communication with the public, respecting the most vulnerable populations and attempting to minimize the disproportionate burden on them.

Keywords COVID-19 · Prevention and control . Bioethics $\cdot$ Socioeconomic factors

\section{Introduction}

Only a few months after the emergence of SARS-CoV-2, the pandemic was already exerting great pressure on countries' health systems. To slow down transmission and allow health systems some time to prepare for a surge in cases that would quickly overwhelm them, countries adopted prevention strategies. In March 2020, Brazilian states started implementing physical isolation measures, which, in general, included school closures and suspension of commercial activities except for those related to food and health. Movement was limited to essential activities. A month later, 60 per cent of the Brazilian population was in physical isolation, with variability across the states (InLoco 2020).

In this paper we discuss ethical aspects of implementing physical distancing in Brazil, as well as potential barriers and facilitators, in light of political, socio-economic, and scientific dimensions. 


\section{Political dimension}

Adherence to public health measures largely relies on the public's trust in health systems. Brazil's public health system, the Sistema Único de Saúde or Unified Health System (SUS), guarantees universal access to healthcare. Primary care, routine immunization, and the HIV comprehensive care programmes are some of its success stories (Castro et al. 2019). Research has shown that utilization of healthcare services, including for prevention, even if unequally across the regions, has increased overall in the past thirty years (Viacava et al. 2018). Nevertheless, there has been a decline in the previously very high immunization coverage across the country (Fujita et al. 2018). Austerity measures and underfunding of SUS in the past years may help explain less vaccinepreventable diseases campaigns and the observed lower vaccination rates (Fujita et al. 2018; Massuda et al. 2018; Paim 2018). The resurgence of dengue in the country in the 1980s revealed the decreased efforts in improving sanitation in poorer settings, and the focus for dengue control has since been put largely on individuals and their ability to implement their own prevention methods, instead of placing the responsibility on governments to address underlying infrastructure problems (Löwy 2017). In the 2010s new viruses entered the country producing Chikungunya outbreaks and also laying the grounds for the Zika global health emergency in 20152016 (Matta et al. 2019). The arbovirus control strategy set the stage for the current COVID-19 response in which the governments ask societies to play their part and stay home to tackle COVID-19, without providing them with the necessary support. Along with cuts in funding, the public's trust in the system may also have diminished, interfering with adherence to implemented public health measures to prevent COVID-19 spread. In April, 54 per cent of Brazilian adults interviewed thought physical distancing would not help contain the advancement of the pandemic (Ipsos 2020).

We have witnessed a political polarization of COVID19 response and a lack of clear federal public health measures to tackle the pandemic, undermining the potential positive effects of a harmonized response. Inconsistent prevention messages from government leaders, instability of health leadership at federal level, and lack of coordination of response across the administrative levels may have led to the public's distrust, thus affecting their response. Furthermore, the failure of political coordination between federal and state governments is a critical moral issue and a source of misinformation. The moral face of the state institutional component, not only in Brazil, is unfortunately immersed in misuse of political power and opportunism, at high costs for populations and the planet.

\section{Socioeconomic Dimension}

Adherence to prevention measures largely depends on social, cultural, and economic factors such as job security, housing, means of transportation, childcare options, and tensions between individual rights and collective protection, among others. Crises such as pandemics will inevitably hit the most vulnerable harder. In particular, if people are deprived of their freedom of movement in a situation of physical isolation, those under no financial security will be most at risk for further impoverishment. This concern has been raised during the COVID-19 pandemic (Ahmed et al. 2020) and is of utmost relevance for Brazil, where more than thirteen million people live in extreme poverty, defined as living below U.S. $\$ 2$ per day (IBGE 2019). Recent estimates for Brazil reveal an unemployment rate of 12 per cent, with over 40 per cent of the working population in informal employment (PNAD/IBGE 2020). This unemployment rate does not include the so-called disillusioned - that is, those who are available to work and would like to but have no expectation of finding work (IBGE 2020). Reasons why people give up looking for work include not finding work in the region, not finding adequate work, and not getting a job due to being considered too young or too old or because of no professional experience or qualifications. Additionally, about 11.5 million Brazilians live in houses with more than three people per bedroom (PNAD/IBGE 2020).

The federal government has put in place social incentives to support families during the COVID-19 crisis, with several limitations to access them. Furthermore, these incentives had their implementation delayed and are planned to be paid for three months only, when financial constraints are expected to last for longer (Folha de São Paulo 2020). Even among those eligible to receive the incentive, many have reported difficulties accessing the benefit. As a result, many people are lining up at the banks - in contravention of physical distancing guidance (G1 2020). As previously mentioned, the federal government started implementing economic constraints in 2019 based on an ultra-neoliberal agenda, radically reducing social protection investments like 
health, education, social security, science, and technology. There are critical ethical issues related to facing and responding to the socioeconomic repercussions of physical distancing in low- and middle-income countries (LMICs) such as Brazil. In a society embodying immense structural inequities, the scope and density of social and sanitarian justice could be the edge between life and death to the most vulnerable.

\section{Scientific Dimension}

Large-scale physical distancing measures were put in place early in Wuhan, at the start of the SARS-Cov-2 outbreak. At that point, little was known about the effectiveness of such measures, and ethical issues were raised concerning curbing people's right to move freely. Months later, there is at least preliminary evidence that such measures have been successful in decreasing COVID-19 transmission (Prem et al. 2020; Nussbaumer-Streit et al. 2020). To be ethically sound, the implementation of these physical distancing measures needs to be evidence-based, and evaluated and updated as we build collective knowledge on the pandemic (WHO 2020a).

Guidance from World Health Organization (WHO) highlights the role of testing for SARS-CoV-2 infection in the control of the pandemic. The response should be based on identifying and caring for COVID-19 patients and quickly identifying their contacts, who can then monitor themselves for symptoms and self-isolate (WHO 2020b). In Brazil there has not been a harmonized testing strategy, and testing overall has been very limited. At the end of April 2020, there had been 0.63 tests/1000 inhabitants, as compared to $12.0 /$ 1000 in the United States and 25.0/1000 in Germany (BBC News Brasil 2020). Improving testing capacity, coupled with ensuring adequate care for COVID-19 patients, would potentially facilitate the assessment of the pandemic impact in the various communities and redirect public health measures accordingly.

Finally, during a sanitary emergency, decisions need to be made according to scientific knowledge. The president, unfortunately, who does not express confidence in science, has made fighting the pandemic more challenging, as he has been acting against physical isolation guidance.

\section{How to Ethically Promote Restrictive and Physical Distancing Measures}

Measures to restrict the individual right to freely move are supported by an argument that collective interests should precede individual interests. This statement, however, is not equally accepted in different societies as well as in different historical contexts. Discourse ethics (Habermas 1990) provides an excellent framework for this analysis, as it assigns the task of defining what is right or wrong, what is just or unjust, to those who are affected by the norm. On this basis, the stringent standards that apply would be those that find acceptance by all those affected by it. In other words, the validity of the norm should not be conditioned by the interests of the most powerful or the most numerous but potentially by the interests of all. Thus, we intend to defend a theory of ethics of mutual respect that would justify the possibility of accepting as correct, in principle, the hypothesis of establishing limitation of the individual right to freely move, as long as equal conditions are established for everyone affected by the norm. In principle, this condition is fulfilled when there is no exception for the physical distancing measures put in place based on who is affected.

The difficulties in achieving physical distancing in the poorest Brazilian communities reflect the conditions to which these population segments are subjected: overcrowded housing, inadequate sanitation, and little or no financial leverage. Hence, to respect the ethics of reciprocity, we must offer conditions so that the most vulnerable receive additional resources to help them comply with such measures. Considering that the social involvement of members of these communities is also desirable, it is necessary to listen to them and meet their needs. Favelas (slums) have demonstrated excellent organization and action capacity during COVID-19. However, governments rarely see their organizations as valid interlocutors, undermining communities' chances of having their voices heard.

Trust in health authorities and scientists has a major role in public acceptance of public health measures, as noted during the H1N1 pandemic by Freimuth et al. (2013). Trust is established through relationships built over time and should not be merely expected based merely on government or public health institutions' exercise of authority (Dawson et al. 2020). Trustworthiness is not established by decree. Quite the opposite, trustworthiness develops when authorities' 
commitment, honesty, and concern are perceived by the public (Freimuth et al. 2013). O'Neill has argued that rather than invest in increasing trust per se, we should aim at enhancing trustworthiness in our societies (O’Neill 2002). In particular during this sanitary emergency, when the trustworthiness of governments and public health agencies are the same time being challenged and heightened in relevance, we've witnessed authorities fail to achieve and stimulate the public's trust. Unfortunately, sometimes, they are doing the opposite, spreading misinformation and distrust.

Each country will have its own challenges and social and cultural specificities when implementing public health measures to contain the COVID-19 pandemic. We support an inclusive and equitable approach to public health measures that respects most vulnerable populations and attempts to minimize the disproportionate burden on them, as previously proposed (Berger et al. 2020). There is an ethical duty to protect the most vulnerable in particular during a pandemic. Hence, understanding long-standing vulnerabilities (and how they are modified when facing the pandemic) as well as new ones generated by COVID-19 will define how well we are able to protect them during physical distancing times.

In particular, during an outbreak of this size, there is a need for transparent and inclusive communication with the public, which may require various strategies to reach different populations (WHO 2016). In Brazil, open TV channels are the most used source of information on the pandemic, independent of social class (Ipsos 2020). Communicating reliable information in dialogue with the public enables a true co-construction of understandings and practices - a pandemic narrative that produces public confidence and efficient responses to social and health needs and avoids misinformation and rumours.

From a financial security perspective, WHO advocates for support to mitigate the financial and social impact of restriction of movement (WHO 2016) as part of an ethical response to infectious diseases outbreaks such as the one we're living with. Although social support measures have been put in place in Brazil, these need to be revisited and continuously adapted in light of people's real needs.

\section{Conclusions}

All efforts should be put in place so that the population is well informed during the COVID-19 pandemic and understands the reasons behind physical isolation along with other strategies and feels supported and included in the response. If such measures are accompanied by continuous public dialogue and participative evaluation that assesses both acceptability from the public as well as effectiveness, there is a higher chance the population will trust the health systems implementing them. Trust in health systems is likely to produce a sense of social solidarity and a belief that we are in fact all fighting this pandemic together, despite different conditions and beliefs, and we will have a better chance to succeed.

Funding This work was partially supported by the Wellcome Trust - Grant n. 218750/Z/19/Z.

\section{References}

Ahmed, F., N. Ahmed, C. Pissarides, and J. Stiglitz. 2020. Why inequality could spread COVID-19. Lancet Public Health 5(5): e240.

BBC News Brasil. 2020. Brasil é um dos países que menos realiza testes para covid-19, abaixo de Cuba e Chile [Brazil is one of the least testing countries for COVID-19, below Cuba and Chile]. April 24. https://www.bbc.com/portuguese/internacional52383539. Accessed May 1, 2020.

Berger, Z.D., N.G. Evans, A.L. Phelan, and R.D. Silverman. 2020. Covid-19: Control measures must be equitable and inclusive. BMJ 368: m1141. https://doi.org/10.1136/bmj.m1141.

Castro, M.C., A. Massuda, G. Almeida, et al. 2019. Brazil's unified health system: The first 30 years and prospects for the future. Lancet 394(10195): 345-356.

Dawson A., J.E. Ezekiel, M. Parker, M.J. Smith, and T.C. Voo. 2020. Key ethical concepts and their application to COVID19 research. Public Health Ethics: phaa017. https://doi. org/10.1093/phe/phaa017.

Folha de São Paulo. 2020. Demora nas ações de auxílio e invisibilidade de grupos agravam fome [Delay in aid and invisibility of groups aggravates hunger]. April 10 . https://www1.folha.uol.com.br/equilibrioesaude/2020/04 /demora-nas-acoes-de-auxilio-e-invisibilidade-de-gruposagravam-fome.shtml. Accessed May 1, 2020.

Freimuth, V., D. Musa, K. Hilyard, S. Quinn, and K. Kim. 2013. Trust during the early stages of the 2009 H1N1 Pandemic. Journal of Health Communication 19(3): 321-339.

Fujita, D.M., F.S. Salvador, L.H.S. Nali, and E.J.A. Luna. 2018. Decreasing vaccine coverage rates lead to increased vulnerability to the importation of vaccine-preventable diseases in Brazil. Journal of Travel Medicine 25(1): tay100.

G1. 2020. Com problemas para obter auxílio emergencial, trabalhadores geram filas nas agências da Caixa no ES [With problems obtaining aid, workers queue at Caixa branches in ES]. April 22. https://g1.globo.com/es/espiritosanto/noticia/2020/04/22/com-problemas-para-obter-auxilioemergencial-trabalhadores-geram-filas-nas-agencias-dacaixa-no-es.ghtml. Accessed May 1, 2020. 
Habermas, J. 1990. Moral consciousness and communicative action. Maldon: Polity Press.

IBGE (Brazilian Institute of Geography and Statistics). 2019. Extrema pobreza atinge 13,5 milhões de pessoas e chega ao maior nível em 7 anos [Extreme poverty reaches 13.5 million people-its highest level in 7 years]. https://agenciadenoticias.ibge.gov.br/agencia-noticias/2012agencia-de-noticias/noticias/25882-extrema-pobreza-atinge13-5-milhoes-de-pessoas-e-chega-ao-maior-nivel-em-7anos. Accessed June 28, 2020.

InLoco. 2020 . COVID-19 Brazilian map . https://mapabrasileirodacovid.inloco.com.br/pt/.

Ipsos. 2020. Many think it's unlikely the economy will recover quickly once COVID-19 lockdown is over. News, April 17. https://www.ipsos.com/en/many-think-its-unlikelyeconomy-will-recover-quickly-once-covid-19-lockdownover. Accessed May 1, 2020.

Löwy, I. 2017. Leaking containers: Success and failure in controlling the mosquito Aedes aegypti in Brazil. American Journal of Public Health 107(4): 517-524.

Matta, G.C., C. Nogueira, E.T. Rabello, and L.N. Silva. 2019. Zika outbreak in Brazil: In times of political and scientific uncertainties, mosquitoes can be stronger than a country. In Framing animals as epidemic villains: Histories of nonhuman disease vectors, edited by C. Lynteris, 211-228. Palgrave Macmillan.

Massuda, A., T. Hone, F.A.G. Leles, M.C. Castro, and R. Atun. 2018. The Brazilian health system at crossroads: Progress, crisis and resilience. BMJ Global Health 3(4): e000829.

Nussbaumer-Streit, B., V. Mayr, A.I. Dobrescu, et al. 2020. Quarantine alone or in combination with other public health measures to control COVID-19: A rapid review. Cochrane Database of Systematic Reviews 4: CD013574.

O'Neill, O. 2002. A question of trust: The BBC Reith Lectures 2002. Cambridge: Cambridge University Press.
Paim, J.S. 2018. Sistema Único de Saúde (SUS) aos 30 anos [Thirty years of the unified health system (SUS)]. Ciência \& Saúde Coletiva 23(6): 1723-1728.

PNAD/IBGE. 2020. Pesquisa Nacional Por Amostra de Domicílios Contínua - PNAD Contínua - IBGE [Continuous national household sample survey]. https://www.ibge.gov. br/estatisticas/multidominio/condicoes-de-vida-desigualdadee-pobreza/17270-pnad-continua.html?=\&t=series-historicas.

Prem, K.,Y. Liu, T.W. Russell, et al. 2020. The effect of control strategies to reduce social mixing on outcomes of the COVID-19 epidemic in Wuhan, China: A modelling study. The Lancet Public Health 5(5): E261-E270.

Viacava, F., R.A.D. Oliveira, C.C Carvalho, et al. 2018. SUS: Oferta, acesso e utilização de serviços de saúde nos últimos 30 anos [SUS: Supply, access to and use of health services over the last 30 years]. Ciência \& Saúde Coletiva 23(6): 1751-1762.

WHO. 2016. Managing ethical issues in infectious disease outbreaks. http://www.who.int/ethics/publications/infectiousdisease-outbreaks/en/.

- 2020a. Considerations in adjusting public health and social measures in the context of COVID-19. https://www. who.int/publications/i/item/considerations-in-adjustingpublic-health-and-social-measures-in-the-context-of-covid19-interim-guidance.

- 2020b. Considerations in the investigation of cases and clusters of COVID-19. https:/www.who.int/publicationsdetail/considerations-in-the-investigation-of-cases-andclusters-of-covid-19.

Publisher's note Springer Nature remains neutral with regard to jurisdictional claims in published maps and institutional affiliations. 